\title{
EVENT HIBURAN BAGI TKI DI TAIWAN SEBAGAI PENCITRAAN PADA ANGGOTA KOMUNITAS
}

\author{
Ulani Yunus \\ Marketing Communication Department, Faculty of Economic and Communication, BINUS University \\ Jln. K.H. Syahdan No. 9, Palmerah, Jakarta Barat 11480 \\ uyunus@binus.edu
}

\begin{abstract}
Event is still a useful media for building good image for certain communities. In addition to functioning as a media ritual, an event which is published through a live broadcast mass media will also increase the brand image of a particular product. Research question in this article is: what are the kinds of the TKI Event held in Taiwan in 2013 and what elements of the event that brings TKI enthusiastic in Taiwan? The method used in this study is a qualitative interpretive. The data was collected through direct observations and impressions of social media such as youtube as well as literature from the source journal from previous research literature or books that support research topic. Conclusion of the study states that the type of event held by workers in Taiwan is a talent contest and stage entertainment. While elements of the event that brings enthusiastic for workers is an event that displays imagery figure, and the appearance of celebrities.
\end{abstract}

Keywords: Event, Reputation, TKI

\begin{abstract}
ABSTRAK
Event masih dapat dijadikan sebagai media yang bermanfaat dalam pencitraan bagi komunitas tertentu. Selain memiliki fungsi sebagai media ritual, event yang dituangkan melalui siaran langsung media massa akan juga menambah brand image produk tertentu. Pertanyaan penelitian dalam artikel ini adalah: Event TKI apa saja yang diselenggarakan di Taiwan pada tahun 2013 serta unsur apa saja dalam event yang mendatangkan antusias TKI di Taiwan?Metode yang digunakan dalam penelitian ini adalah kualitatif interpretatif. Pengumpulan data dilakukan melalui observasi langsung dan tayangan media sosial seperti youtube serta studi pustaka dari sumber jurnal hasil penelitian sebelumnya ataupun buku literatur pendukung topik penelitian. Kesimpulan hasil penelitian menyebutkan bahwa jenis event yang diselenggarakan oleh TKI di Taiwan adalah lomba bakat dan hiburan panggung. Sedangkan unsur event yang mendatangkan antusias bagi TKI adalah event yang menampilkan pencitraan figur, dan penampilan selebritis.
\end{abstract}

Kata kunci: Event, Pencitraan, TKI 


\section{PENDAHULUAN}

Berada di negeri orang untuk jangka waktu lama membutuhkan proses adaptasi dan keberanian untuk terus bertahan. Apalagi bagi mereka yang tidak pernah jauh dari keluarga sebelumnya. Ada kemungkinan terkendala dalam komunikasi lingkungan serta dengan komunitasnya. Budaya orang Indonesia, terutama dari suku Jawa, Sunda dan Betawi yang senang berkumpul dengan saudara dan kerabat dekat akan lebih sulit menjalankannya. Baik individu yang bersangkutan ataupun keluarganya (contoh: orang tua). Disebutkan oleh Shahab bahwa orang tua di Betawi takut anaknya merantau karena jika kemudian meninggal, mereka tidak sempat melihat jenazahnya (Shahab, 2001).

Di sisi lain, kesediaan tenaga kerja dalam negeri juga sangat terbatas untuk yang tingkat pendidikan rendah (di bawah SMA). Peluang untuk bekerja di luar negeri justru menawarkan hal yang berbeda. Tenaga kerja Indonesia (TKI) menjadi lebih diinginkan di luar negeri dibandingkan di dalam negeri sendiri. Namun seperti disebutkan sebelumnya bahwa mental untuk berada di negeri orang dan berada jauh dari keluarga membuat sebagian calon TKI merasa sulit untuk memutuskan keberangkatan mereka dalam mendulang kesempatan bekerja di luar negeri. Salah satu negara yang tampak sangat membutuhkan keberadaan TKI adalah Taiwan.

Dalam upaya memelihara agar para TKI betah berada di Taiwan, mereka diperlakukan secara istimewa oleh pemerintah setempat dan juga oleh para pengelola TKI yang berada di Taiwan. Perlakuan istimewa ini terlihat dari undang-undang yang disusun pemerintah Taiwan bagi para tenaga kerja asing di negaranya. (Yunus, Budihardjo, Hartanto, 2013). Event yang dilaksanakan dalam pengamatan peneliti menjadi alat bagi pencitraan di kelompok anggota komunitas TKI. Bulan Februari merupakan awal untuk pelaksanaan program public relations, sedangkan bulan Agustus adalah hari kemerdekaan RI sehingga menjadi momen penting bagi setiap orang Indonesia di mana saja berada.

Event tetap dijadikan sebagai media yang bermanfaat dalam pencitraan bagi komunitas tertentu seperti yang disebutkan oleh Xi Cui. Cui mengatakan bahwa events sebagai media, bahkan sebagai media ritual dalam pelaksanaan olimpiade Beijing. Selain memiliki fungsi sebagai media ritual, event yang dituangkan melalui siaran langsung media massa akan juga menambah brand image produk tertentu untuk komunitas (Xi, 2012) Dengan latar belakang di atas, maka pertanyaan penelitian dalam artikel ini adalah: Event TKI apa saja yang diselenggarakan di Taiwan pada tahun 2013 serta Unsur apa saja dalam event yang mendatangkan antusias TKI di Taiwan? Dengan demikian tujuan dari penelitian ini: (1) Untuk mengetahui jenis Event TKI apa saja yang diselenggarakan di Taiwan tahun 2013. (2) Untuk mengetahui unsur event apa yang dapat menciptakan antusias TKI di Taiwan.

Penelitian ini fokus pada event hiburan bagi TKI di Taiwan sebagai pencitraan bagi anggota komunitas. Dengan demikian, hasil penelitian ini diharapkan mampu memberikan sumbangansumbangan berikut: (1) memberikan masukan bagi pemerintah Republik Indonesia untuk dapat merangkul para TKI di melalui event; (2) memberi masukan kepada para pengelola TKI di luar Taiwan agar memanfaatkan event sebagai media komunikasi; (3) memberikan sumbangan ilmu tentang penyelenggaraan event di luar negeri yang ditujukan bagi kalangan TKI.

\section{METODE}

Metode yang digunakan dalam penelitian ini adalah kualitatif interpretatif. Pengumpulan data dilakukan melalui observasi langsung dan tayangan media sosial seperti youtube serta studi pustaka dari sumber jurnal hasil penelitian sebelumnya ataupun buku literatur pendukung topik penelitian. Hasil observasi dinyatakan sebagai data primer yang diinterpretasikan oleh peneliti, sedangkan data 
sekundernya berupa data yang dikutip dari sumber-sumber penelitian tidak langsung. Data tersebut diolah menjadi bahan analisis bagi peneliti. Keabsahan penelitian ini terletak pada sumber-sumber yang dijadikan sumber data dalam penelitian ini.

\section{HASIL DAN PEMBAHASAN}

Ada berbagai event yang dilaksanakan dalam masyarakat, namun dalam penelitian ini mengarah pada event yang sifatnya hiburan. Event hiburan adalah event yang tujuannya menyenangkan audiens dengan perencanaan dan koordinasi dari penyelenggara. Situasi yang dirasakan mendatangkan keamanan dan kenyamanan dengan pola yang telah ditetapkan (Carter, 2013). Dengan demikian, event bagi TKI harus mendatangkan rasa senang dalam situasi yang nyaman dan aman. Jadi dalam pelaksanaannya, event yang diselenggarakan sifatnya harus menyenangkan bagi para peserta yang terlibat. Dengan ini, kategori event akan terlihat dari antusias para audiens yang ada pada event tersebut.

TKI di Indonesia menurut Dewitt dan Hernandez memiliki potensi ekonomi bagi negara, sehingga mereka turut serta dalam menentukan pendapatan negara. Menurut penelitian mereka, TKI lebih banyak memilih Malaysia sebagai negara pilihan bekerja dibandingkan dengan negara lainnya. Malaysia memiliki jarak yang dekat dengan Indonesia selain juga memiliki agama yang sama dengan para TKI. (Dewitt \& Hernandez, 2003). Dengan demikian, TKI yang berada di Taiwan tentunya memiliki karakter khas yang unik untuk diamati mengingat bahwa jarak antara Indonesia dan Taiwan yang relatif jauh (5 jam penerbangan pesawat terbang) serta agama dan kebudayaan yang berbeda dengan mayoritas penduduk Taiwan, selain juga persoalan bahasa yang unik dalam interaksi antara TKI dengan majikannya. Penduduk Taiwan menggunakan Bahasa Mandarin dalam keseharian termasuk dalam tulisannya.

Di tengah persoalan yang mungkin terjadi pada TKI karena jarak demografis antara Indonesia dengan Taiwan, maka event dapat membantu menjadi solusi bagi konflik psikologis yang mungkin terjadi pada diri TKI itu sendiri. Menurut Matthews bahwa ada hubungan antara reputasi dengan hubungan baik dengan pihak tertentu. Semakin baik interaksi antara dua pihak, semakin baik reputasi yang tercipta. Dengan demikian, event yang diselenggarakan secara efektif dapat membantu hubungan antar anggota komunitas menjadi lebih baik (Matthews, 2012). Event harus bersifat menghibur dan menciptakan rasa aman dan nyaman bagi para TKI.

Para TKI di Taiwan menjadi komunitas tersendiri karena mereka memiliki kebutuhan untuk saling berinteraksi. Menurut Jasmadi, komunitas adalah kelompok orang yang saling berinteraksi yang berada di lokasi tertentu. Komunitas ini memiliki empat ciri, diantaranya adalah adanya ikatan emosional (Jasmadi, 2006). Dalam hal ini para TKI adalah komunitas orang Indonesia yang bekerja di Taiwan baik pekerja di sektor formal ataupun sektor informal. Namun mayoritas TKI yang berada di Taiwan adalah pekerja di sektor informal seperti pengasuh manula, dll.

Taiwan merupakan negara yang dijadikan bahan penelitian dan tulisan beberapa penulis dari barat, diantaranya adalah oleh Rubinstein yang menyebutkan bahwa Taiwan sebagai negara yang layak dijuluki "too big to ignore". Taiwan dalam pandangan mereka adalah negara yang memiliki sektor ekonomi terdepan, memiliki hubungan dengan dunia luas melalui pengembangan pengetahuan, permodalan, teknologi dan sumber daya manusia (Rubenstein, 2007). Keunggulan Taiwan tampak pada teknologi informasi yang bisa merambah pasar di beberapa negara Asia, termasuk Indonesia. Merek komputer produksi Taiwan yang terkenal di Indonesia adalah ASUS. Industri ini juga memperkerjakan TKI. 


\section{Event untuk TKI di Taiwan Tahun 2013}

\section{Event Lomba Bakat TKI pada Bulan Februari 2013}

Lomba ini diselenggarakan di Taipei City Mall pada hari Minggu, 13 Februari 2013. Acara disponsori oleh Index, salah satu jasa pengiriman uang para TKI dari Taiwan ke Indonesia. Target acara ini adalah untuk menggali potensi para TKI sekaligus menjadi ajang hiburan dan ekpresi diri para TKI di negeri orang. Terjaring ada 16 peserta TKI yang lolos dari audisi selama dua bulan. Bakat yang paling dominan adalah menyanyi dan menari, namun selain itu juga ada peserta yang berbakat menulis. Acara terselenggara meriah karena ada peserta dengan bakat menulis tetapi juga mengalunkan lagu dangdut. Tarian yang muncul dalam acara lomba ini adalah tarian khas dari Jawa Barat, yaitu Jaipong. Para TKI yang menjadi pemenang mendapat hadiah berupa produk elektronik dan juga telepon genggam.

Program seperti ini merupakan teknik public relations yang biasanya diselenggarakan untuk branding produk elektronik ataupun telekomunikasi. Jika peka terhadap kebutuhan ini, maka pasar para TKI di Taiwan, event ini menjadi salah satu cara branding merek-merek produk elektronik tertentu sekaligus menjadi pencitraan. Seperti yang disebutkan oleh bahwa "Pioneers of many $P R$ techniques came from industries like electric utilities, broadcasting and telecommunication." (Lange \& Powell, 2008).

\section{Event Perayaan Hari Kemerdekaan RI para TKI di Taiwan pada Agustus 2013}

Bertempat di lapangan taman Sekolah Dasar Tainan, ribuan TKI merayakan hari Kemerdekaan RI melalui panggung hiburan. Seperti pada umumnya, orang Taiwan menyukai udara yang cerah, event ini berlangsung dalam kondisi cuaca cerah dan sedikit berawan. Pengisi acara berasal dari grup band dan penyanyi dangdut yang belum dikenal baik di Indonesia maupun Taiwan. Namun para TKI tetap histeris dengan lagu-lagu yang dibawakan oleh para pemusik dan penyanyi. Penyelenggara adalah forum perkumpulan para TKI di Taiwan (FKKBWIT) yang dianggap berhasil menjadi motor penggerak kekompakan TKI. Pada saat acara berakhir seluruh panitia membersihkan area bekas acara. Dengan demikian event meninggalkan kesan yang tertib dan rapi. Seharusnya event seperti ini menjadi media public relations (PR) karena dalam situasi yang serba cepat seperti sekarang, banyak tools PR yang dapat dipergunakan untuk menarik perhatian ribuan orang: " Such a practice is merely window dressing, a way to improve public image while detracting attention".(Stole, 2008). Event seperti di atas akan mampu menarik perhatian para TKI, baik dalam komunitasnya sendiri atau untuk pencitraan merek tertentu.

Memilih pengisi acara event merupakan hal yang penting, seperti pada tahun 2011, salah satu event hiburan musik diisi oleh goyangan pedangdut Inul Daratista. Pada event ini, penonton berjumlah 20.000 orang. Dengan demikian sangat efektif untuk menanamkan citra merek tertentu dan juga komunitas TKI di Taiwan. Event hiburan menjadi signifikan karena keberadaan dan situasi psikologis para TKI di Taiwan membutuhkan event ini. Seperti yang diungkap penelitian yang dilakukan oleh Berjot dkk tentang dampak pekerjaan pada stres seseorang. Hasil penelitian menyebutkan bahwa: Situations appraised as being identity-threatening are mostly the same than those found in the stress literature and are stressful because of their impact on personal identity. (Berjot et al, 2013).

Dalam pekerjaan yang berat dan menimbulkan stres juga berdampak pada identitas personalnya. Para TKI yang berada di Taiwan membutuhkan kinerja yang baik demi kelanggengan dalam kontrak kerjanya. Jika terdapat permasalahan dalam proses mereka bekerja, akan menimbulkan stres tersendiri dalam bentuk yang berbeda karena juga berhubungan dengan identitasnya sebagai TKI. Dengan kedua event di atas, maka dapat ditemukan bahwa jenis event yang biasanya dilaksanakan untuk TKI di Taiwan adalah event lomba dan panggung musik. Walaupun ditemukan jenis event yang 
bersifat religius, seperti dakwah atau tausiyah (ceramah agama Islam), dalam peneltian ini, hanya dibahas event lomba dan musik dangdut saja.

\section{Unsur event yang dapat Mendatangkan Antusias TKI di Taiwan}

Menyimak dari dua event yang dibahas di atas, maka dapat ditemukan unsur yang dapat mendatangkan antusias para TKI Taiwan. Unsur-unsur itu adalah Pencitraan Figur dan Penampilan Artis.

\section{Pencitraan Figur}

Sebagai TKI yang merantau berada di negeri orang lain. Mereka membutuhkan figur bagi diri mereka sendiri, hal ini terlihat dari nyanyian-nyanyian yang dilantunkan dan tarian daerah yang mereka bawakan. Lomba-lomba bakat mendatangkan antusias tersendiri bagi TKI karena mendapatkan kesempatan tampil sebagai figur perwakilan Indonesia. Dalam sebuah penelitian dengan perspektif PR, penampilan Obama dengan kegiatan olah raga selain sebagai presiden menjadi menarik dan menimbulkan antusias bagi masyarakat luas, karena figur Obama hadir dengan image maskulin. Hal ini penting bagi masyarakat Amerika untuk memperkuat maskulinitas negara Amerika. Maskulin identik dengan kekuatan (Moore \& Dewberry). Maka dalam event yang dimunculkan sebaiknya menampilkan figure identitas kewarganegaraan, seperti tari atau lagu daerah. Lomba pencarian bakat ini, sebaiknya mengusung tema dengan unsur-unsur daerah seperti lomba lagu atau tari daerah daripada sekedar menyanyikan lagu dangdut oleh para peserta lomba.

\section{Penampilan Artis}

Dalam penelitian sebelumnya (Yunus, Budihardjo dan Hartanto, 2013) menyebutkan bahwa TKI di Taiwan secara psikologis juga mengalami tekanan yang cukup hebat. Oleh karena itu, mereka membutuhkan fasilitator untuk mengurangi rasa stresnya tersebut. Unsur event yang dapat mendatangkan antusias bagi para TKI, sesuai dengan observasi adalah adanya penampilan artis. Terbukti ada perbedaan, ketika acara musik diisi oleh band dan penyanyi kurang ternama, antusias dari para TKI masih ada, namun pengunjung tidak sebanyak ketika event diisi oleh Inul Daratista.

Adanya artis dengan penampilan yang khas, menimbulkan dampak untuk mengurangi perasaan tertekan para TKI. Stitz dan Pierce, Jr (2013) menuliskan bahwa "A central component of body image and bodily satisfaction is physical appearance". Penampilan para artis yang secara fisik biasanya menjadi idola fans nya, dapat menjadi unsur yang mengurangi perasaan tertekan dari para TKI. Dengan demikian, penampilan artis dapat menjadi unsur event yang mendatangkan antusias para TKI.

\section{SIMPULAN}

Hasil dan pembahasan tentang "Event Hiburan bagi TKI di Taiwan sebagai Pencitraan pada Anggota Komunitas" mengarahkan pada kesimpulan bahwa jenis event TKI yang ada di Taiwan adalah event lomba bakat dan panggung hiburan. Sedangkan unsur event yang mendatangkan antusias bagi TKI adalah adanya unsur pencitraan figur dan penampilan artis. Dengan demikian, dalam penyelenggaraan event bagi TKI, kedua unsur tersebut harus menjadi pertimbangan sehingga mendatangkan antusias bagi calon pengunjung. 


\section{DAFTAR PUSTAKA}

Berjot, S., Altintas, E., Lesage, F. X., Grebot, E. (2013). The Impact of Work Stressors on Identity Threats and Perceived Stress: An Exploration of Sources of Difficulty at Work Among French Psychologists. SAGE Open, 3(3).

Carter, L. (2013). Event Planning 2nd Edition. Diakses dari books.google.co.id/books?isbn= 1481701622

Dewitt, D. B., Hernandez, C. G. (2003). Development and Security in Southeast Asia: The people. Diakses dari books.google.co.id/books?isbn=0754617912

Jasmadi \& E-media Solusindo. Membangun Komunitas Online Praktis Gratis. Diakses dari books.google.com/books?isbn=9792735240

Lange , D. L., Powell, H. J. (2008). No Law: Intellectual Property in the Image of an Absolute First Amendment. London: Stanford Law Books.

Matthews, D. (2008). Special Event Production: The Process. Diakses dari books.google.com/books?isbn=0750682434

Moore, A. J., Dewberry, D. (2012). The Masculine Image of Presidents As Sporting Figures: A Public Relations Perspective SAGE Open, 2(3).

Rubinstein, M. A. (2007). Taiwan: A New History. Diakses dari books.google.com/books?isbn=0765614952

Shahab, A. (2001). Robinhood Betawi: Kisah Betawi Tempo Doeloe. Diakses dari books.google.com/books?isbn=9793210001.

Stole, I. L. (2008). Philanthropy as Public Relations: A Critical Perspective on Cause Marketing. International Journal of Communication, 2

Stitz M. E., Pierce, J. D. Jr. (2013). Changes in Appearance in the Presence of Major Stress Events. SAGE Open, 3(2).

Yunus, U., Budihardjo, H. S., Hartanto, B. (2013). The Government Communication Model with Indonesian Workers in Taiwan. Twelfth International Conference on New Directions in the Humanities: Universidad CEU San Pablo Madrid, Spain

Xi, C. (2013). Media Events Are Still Alive: The Opening Ceremony of the Beijing Olympics as a Media Ritual. International Journal of Communication 7, 1220-12351932-8036/20130005 